\title{
COMPACT RECTANGULAR SLOT MICROSTRIP ANTENNA WITH BAND-NOTCHED CHARACTERISTICS FOR ULTRAWIDEBAND APPLICATIONS
}

\author{
Vaishali Varpe, Rekha Labade and Ramesh Pawase \\ Department of Electronics and Telecommunication Engineering,Pune University, \\ Sangamner,Maharashtra,India
}

\section{ABSTRACT}

In this paper, we present an offset microstrip-fed ultrawideband antenna with band notch characteristics.The antenna structure consists of rectangular radiating patch and ground plane with rectangular shaped slot, which increases impedance bandwidth upto 117.73\%(2.9-11.2GHz).A new modified $U$ slot is etched in the radiating patch to create band-notched properties in the WiMAX (3.3$3.7 \mathrm{GHz}$ ) and $\mathrm{C}$-band satellite communication (3.7-4.15GHz).Furthermore, parametric studies have been conducted using EM simulation software CADFEKO suite(7.0) and optimized with stable radiation pattern which satisfied $U W B$ requirement for VSWR $<2$.A prototype of antenna is fabricated on $1.6 m m$ thick FR-4 substrate with dielectric constant of 4.4 and loss tangent of 0.02.The designed antenna exhibits bidirectional and omni directional radiation patterns along E and H-plane with stable gain and efficiency over entire operating band except notch frequency band. Simulated results are in good agreement with the measured results of the proposed antenna which makes it a good candidate for UWB application.

\section{KEYWORDS}

Band Notch,L-Shaped Ground Plane, Modified U-Slot,Ultrawideband(UWB), Slot Antenna.

\section{INTRODUCTION}

According to FCC UWB is a very promising technology that have a large unlicenced bandwidth of $7.5 \mathrm{GHz}$ ranging from $3.1 \mathrm{GHz}$ to $10.6 \mathrm{GHz}$ [1]. Since then UWB communication system has been favourable due to various advantages such as high data transmission rate, low cost and ease of integration. Now-a-days, recent communication systems required single antenna having large impedance bandwidth. In order to enhance wide impedance bandwidth of UWB antenna in that case slot antenna is the important part which satisfy demand of UWB.To improve impedance bandwidth different shapes of slot such as rectangle, circle, elliptical, hexagonal, pentagonal, tapered has been used.

The ultrawideband communication system is entitled to operate within $3.1-10.6 \mathrm{GHz}$ band. There are some narrow band wireless communication systems are exist within the UWB system. These narrowband systems are WiMAX(IEEE802.16) operating in the frequency band of 3.33.7GHz,C-band satellite communication operating in the frequency band of 3.7-4.15GHz,WLAN operating in the frequency band of $5.15-5.825 \mathrm{GHz}, \mathrm{X}$-band satellite communication operating at 7.25-7.75GHz band. These narrow band systems can cause interference to the UWB system. Hence, it is essential to design UWB antenna with band notched characteristics in the frequency band of $3.3-3.7 \mathrm{GHz}, 3.7-4.15 \mathrm{GHz}, 5.15-5.825 \mathrm{GHz}, 7.25-7.75 \mathrm{GHz}$ respectively to reduce interference between WiMAX, C-band, WLAN, X-band and UWB system. 
To reduce this interference,many significant band-notched techniques have been used in UWB antennas,including etching an angle-shaped parasitic slits[2],C-shaped slot and L-shaped stub[3], a pair of S-shaped slits and elliptical ring slot[4], inverted $U$ and fork-shaped parasitic structures[5].Band rejection characteristics are obtained by embedding different shapes of the slots such as a square ring[6] and folded trapezoid[7].In [8]-[9] dual band antenna operating in bluetooth and UWB proposed but without band-notched characteristics.In [10] the UWB antenna with integrated Bluetooth and band-notched characteristics are investigated ,so as to reduce interference between narrowband and UWB systems

In this paper,a compact band-notch UWB antenna is presented.By inserting modified U slot in the radiating patch band notch function from $3.3-4.15 \mathrm{GHz}$ is obtained.The designed antenna is simulated using CADFEKO suite(7.0).By cutting wide rectangular slot from ground plane much wider impedance bandwidth from 2.9 to $11.2 \mathrm{GHz}$ can be obtained.

\section{ANTENNA GEOMETRY AND DESIGN}

Fig.1 describes the evolution of rectangular slot UWB antenna.The basic antenna comprises rectangular patch and ground plane with rectangular slot.The basic rectangular monopole UWB antenna is simulated using FR-4 substrate having compact substrate dimension of $33 \times 35.5 \times 1.6 \mathrm{~mm}^{3}$. Rectangular tunning stub is fed by an offset microstrip line.

To achieve $50 \Omega$ characteristics impedance feedwidth of microstrip line can be calculated using formula (1).

$$
z=\frac{377}{\sqrt{\varepsilon r}[(W / t)+2]}
$$

Here, $\varepsilon \mathrm{r}$ is the dielectric constant of $4.4, w$ is width of feedline, $t$ is thickness of $1.6 \mathrm{~mm}$ and $z$ is characteristic impedance of $50 \Omega$.From all this given data feedwidth of offset microstrip line can be calculated[11][12].

\subsection{Evolution of Rectangular Slot UWB Antenna}

Fig.1(a) shows evolution of UWB antenna for different shape of ground plane and effect of ground plane in terms of bandwidth are discussed using CADFEKO(7.0) EM simulation software[13].Initially for full ground plane less BW(1.98\%) is achieved. For U-shaped ground plane $100.67 \%$ bandwidth is achieved. For partial ground plane $107.30 \%$ bandwidth is achieved. In order to achieve wide impedance bandwidth large rectangular slot is cut from ground to form L-shaped ground which has large impedance bandwidth of $117.73 \%$.This L-shaped ground satisfied demand of UWB. Following formulae are used to calculate percentage of bandwidth.

$$
\begin{aligned}
\% \text { Bandwidth } & =\frac{(F h-F l)}{F c} \\
F c & =\frac{(F l+F h)}{2}
\end{aligned}
$$

Where, $F h$ is higher frequency in $\mathrm{GHz}, F l$ is lower frequency in $\mathrm{GHz}$ and $F c$ is centre frequency in $\mathrm{GHz}$. 


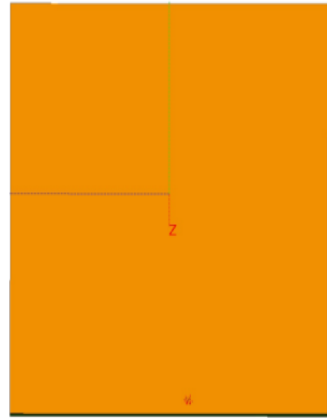

Step 1.(Full ground)

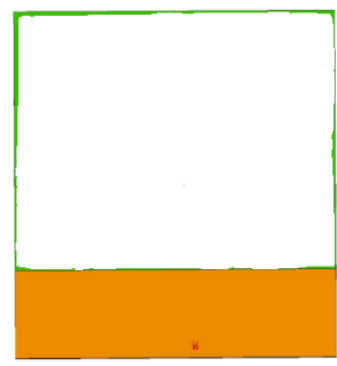

Step 3.(Partial ground)

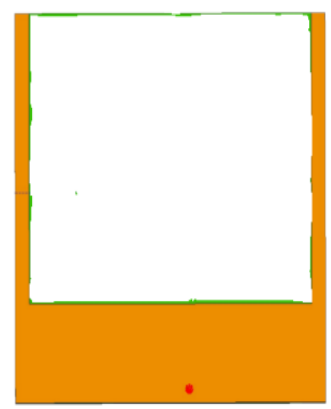

Step 2.(U-shape ground)

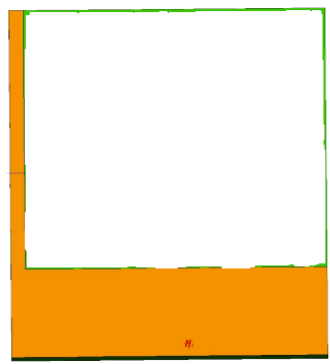

Step 4.(L-shape ground)

(a)

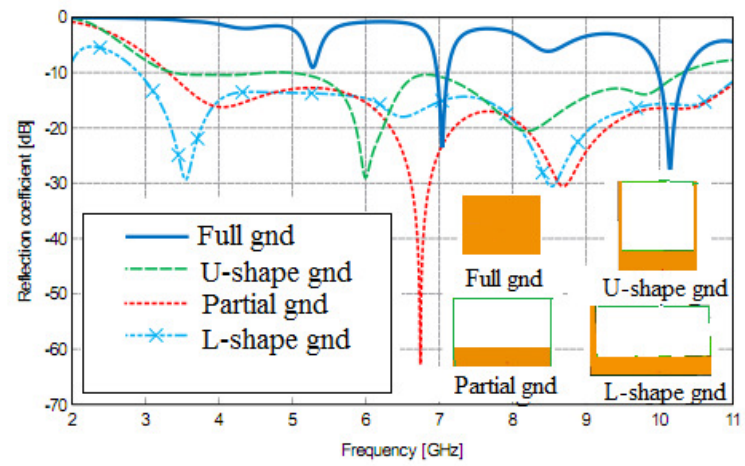

(b)

Figure 1.(a)Evolution of rectangular slot UWB antenna (b)Simulated reflection coefficient for different ground plane

Fig.1(b) shows the simulated results in terms of reflection coefficient $\left(S_{11}\right)$ for different ground plane.Only for L-shaped ground desired impedance bandwidth is obtained.

\subsection{Parametric Study of Rectangular Slot UWB Antenna}

Fig.2 represents the simulated results for different values of width of ground such as $\mathrm{Wg}=1,1.5,2 \mathrm{~mm}$.For all these values of $\mathrm{Wg}$ antenna resonates for entire ultrawideband,but for $\mathrm{Wg}=1.5 \mathrm{~mm}$ return loss is maximum for lower and higher frequency of operation.Hence optimum desired results are obtained for $\mathrm{Wg}=1.5 \mathrm{~mm}$. 


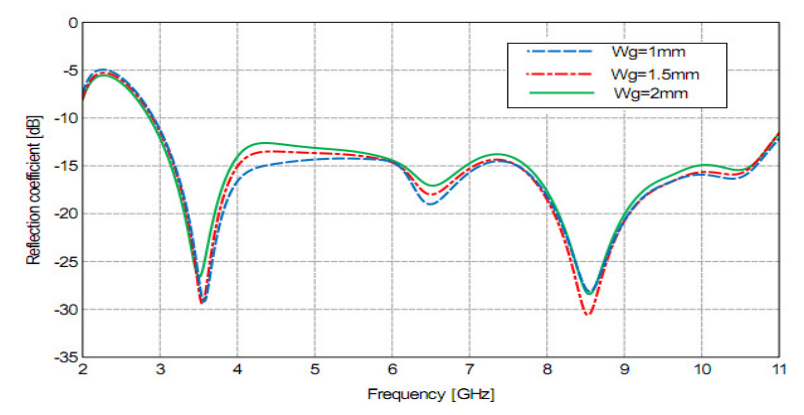

Figure 2.Return loss vs.frequency graph for different width of ground plane

The effect of ground length $(\mathrm{Lg})$ is presented in fig.3.It shows simulated results for different values of length of ground $(\mathrm{Lg})$ such as 8,9 and $10 \mathrm{~mm}$. When $\mathrm{Lg}=8 \mathrm{~mm} \mathrm{~S}_{11}$ gets disturbed at higher frequency range.For $\mathrm{Lg}=10 \mathrm{~mm}$ return loss is very poor at $4.3 \mathrm{GHz}$ frequency.Only for $\mathrm{Lg}=9 \mathrm{~mm}$ we achieved satisfied UWB.

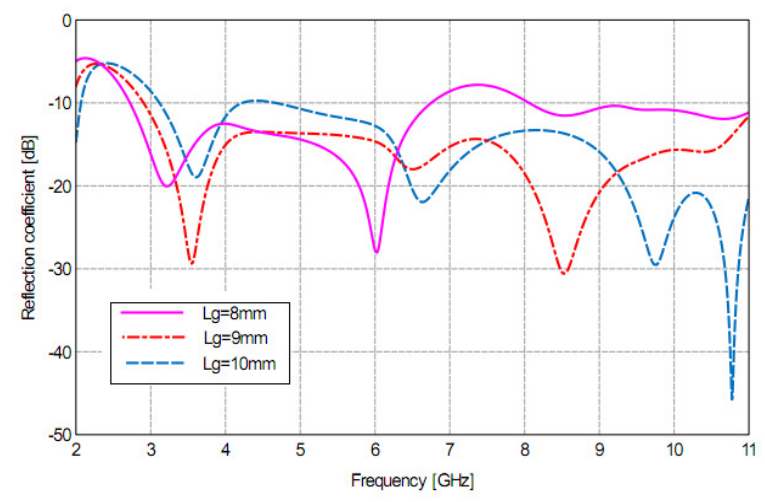

Figure 3.Return loss vs.frequency graph for different length of ground plane

\subsection{Bandnotch Rectangular Slot UWB Antenna}

Fig.4 shows geometry of proposed antenna with band notch characteristics.The design of this antenna is mainly depends on the current distribution as shown in fig.8.The current is mainly concentrated on the radiating patch.In order to obtain band-notch characteristics a new modified U-slot is cut from the radiating patch.After cutting modified U-slot band notch is generated between 3.3 to $4.15 \mathrm{GHz}$. The length of modified U-slot is calculated using equation (4)

$$
\text { Lnotch }=\frac{c}{2 f \sqrt{\text { Ereff }}}
$$

To design the basic geometry of band notch rectangular slot UWB antenna following compact dimensions are used.

$\mathrm{Ws}=33 \mathrm{~mm}, \mathrm{Ls}=35.5 \mathrm{~mm}, \mathrm{Wp}=12 \mathrm{~mm}, \mathrm{Lp}=16 \mathrm{~mm}, \mathrm{Wf}=2.8 \mathrm{~mm}, \mathrm{Lf}=10.25 \mathrm{~mm}, \mathrm{Wg}=1.5 \mathrm{~mm}, \mathrm{Lg}=9 \mathrm{~mm}$, Wslot $=31.5 \mathrm{~mm}$,Lslot $=26.5 \mathrm{~mm}$. 
International Journal Of Microwave Engineering (JMICRO) Vol.1, No.3, July 2016

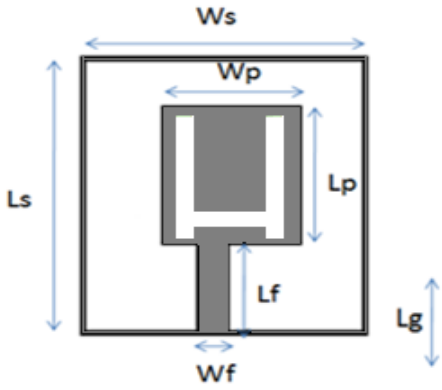

(a)Top View

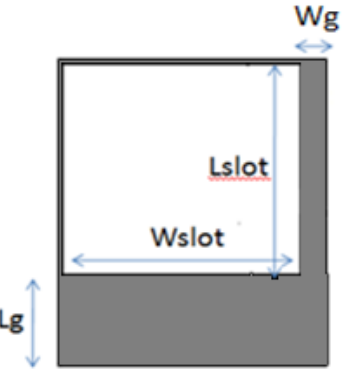

(b)Bottom View

Figure 4.Geometry of band notch rectangular slot UWB antenna

\subsection{Effect of Modified U-Slot Width Variation}

Parametric study of band notch antenna is carried out by changing one parameter at a time and other parameters are remain unchanged.In this study width of modified U-slot is changed.Simulated results are observed for different width of modified $U$ slot such as $0.5 \mathrm{~mm}, 1 \mathrm{~mm}$ and $1.5 \mathrm{~mm}$.It is observed that increase in the slot width results in shifting of resonance frequency.Here only for $1 \mathrm{~mm}$ width of slot highest notching is obtained.

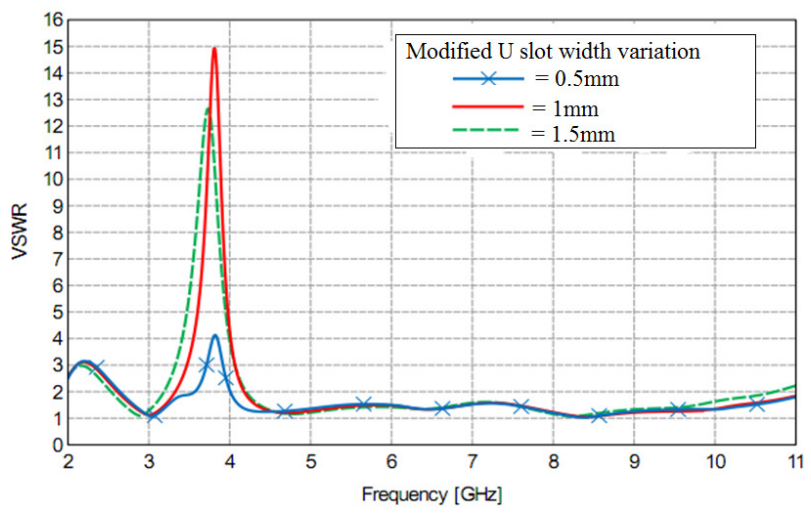

Figure 5.VSWR vs.frequency graph of band notch rectangular slot UWB antenna for different width of modified U slot

\subsection{Efficiency of Bandnotch Antenna}

It is observed that efficiency decreases to $20 \%$ at notch frequency band while above $70 \%$ at other frequencies.Hence from fig. 6 it is clearly observed that antenna filter frequency band from 3.3 to $4.15 \mathrm{GHz}$. 
International Journal Of Microwave Engineering (JMICRO) Vol.1, No.3, July 2016

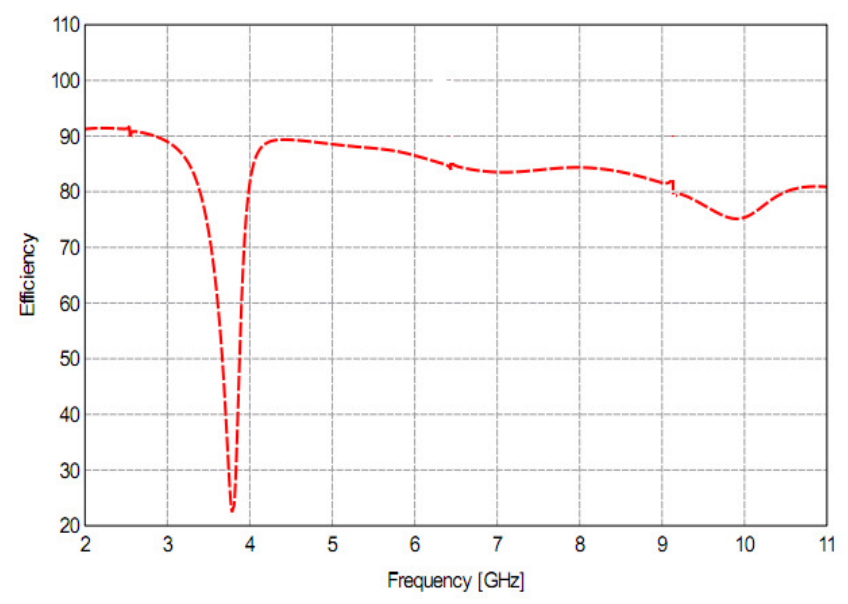

Figure 6.Efficiency vs.frequency graph of band notch rectangular slot UWB antenna

\subsection{Gain of Bandnotch Antenna}

Fig.7 shows gain vs.frequency graph of the designed antenna.It is observed that gain is suddenly dropped at notch frequency band so as to reduce interferences between UWB system and narrowband systems.

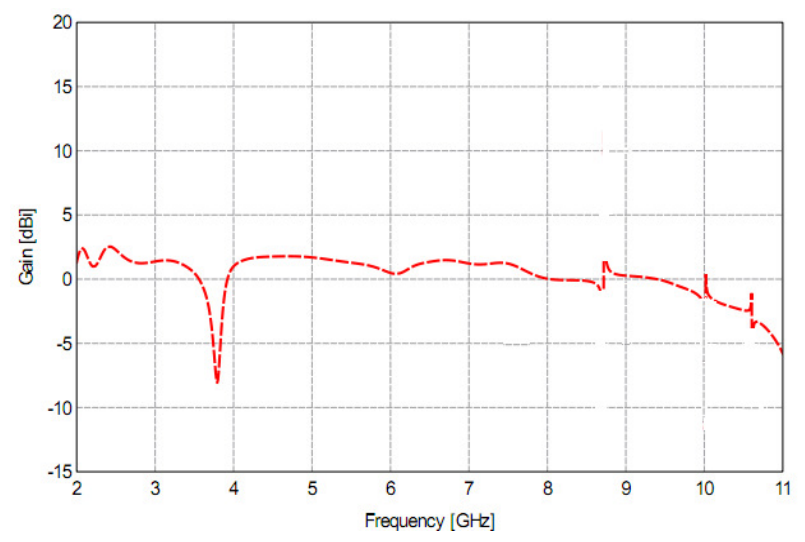

Figure 7.Gain vs.frequency graph of band notch rectangular slot UWB antenna

Fig. 8 shows the surface current distribution at different frequency.It is observed that maximum current flows in modified $\mathrm{U}$ slot at $3.5 \mathrm{GHz}$ notch frequency band as compared to others.

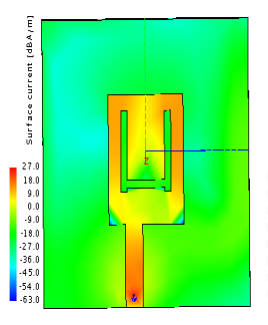

(a) $3 \mathrm{GHz}$

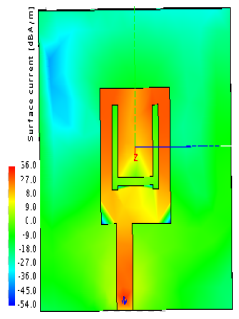

(b) $3.5 \mathrm{GHz}$

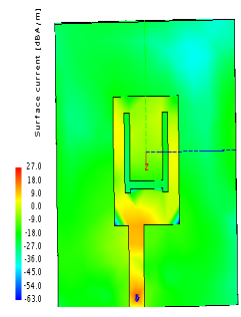

(c) $7.7 \mathrm{GHz}$

Figure 8.Surface current distribution at different frequency of band notch rectangular slot UWB antenna 
Fig.9 shows radiation patterns of band notch antenna at different frequency obtained by simulation software CADFEKO. It is observed that antenna radiation characteristics describe the energy directed by the antenna in azimuth plane $\left(\Phi=0^{\circ}\right)$ and elevation plane $\left(\Phi=90^{\circ}\right)$ at $3.1 \mathrm{GHz}, 5.5 \mathrm{GHz}$ and $10.1 \mathrm{GHz}$ frequencies.It is shown that for all frequencies elevation radiation patterns have almost bidirectional and dipole like radiation patterns because the alternating electric current enters the antenna through feed line and patch junction and leaves the antenna through edges of the radiating patch which results in formation of electric field pattern with maximum field at the radiating edges in the direction of radiation and minimum field at the centre of the patch.The designed antenna is radiated as an omnidirectional in H-plane $\left(\Phi=0^{\circ}\right)$.It is observed that as frequency increases radiation patterns are distorted due to reduction in efficiency at higher frequency range.

- H-plane $\quad$ E plane

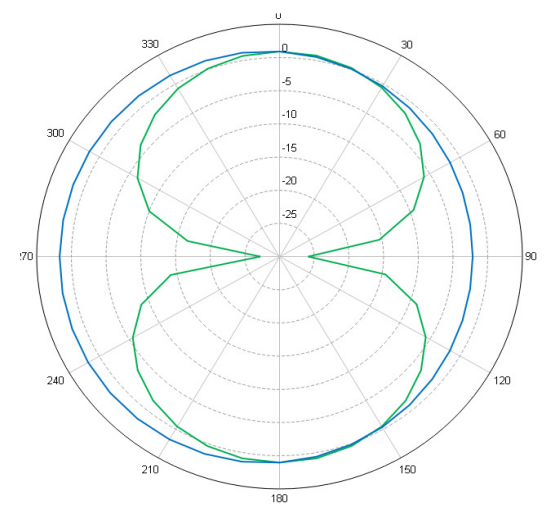

At $3.1 \mathrm{GHz}$

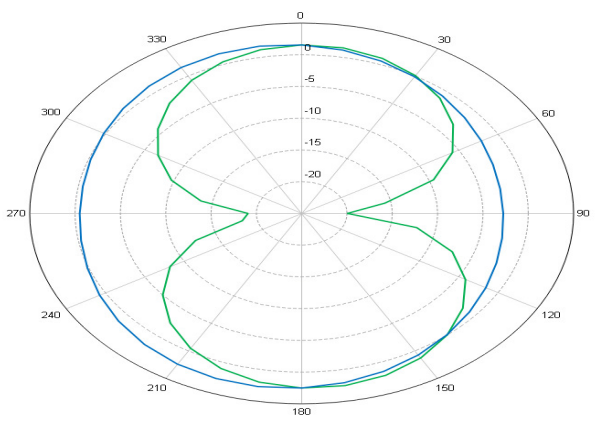

At $5.5 \mathrm{GHz}$

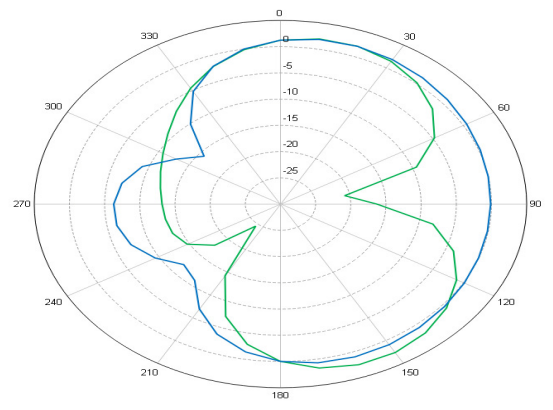

At $10.1 \mathrm{GHz}$

Figure 9.Radiation Patterns at different frequency of band notch rectangular slot UWB antenna 


\section{SIMULATION RESULTS AND DISCUSSION}

Prototype of fabricated bandnotch rectangular slot UWB antenna is shown in fig.10.This prototype of manufactured antenna is compared with a one rupee coin.

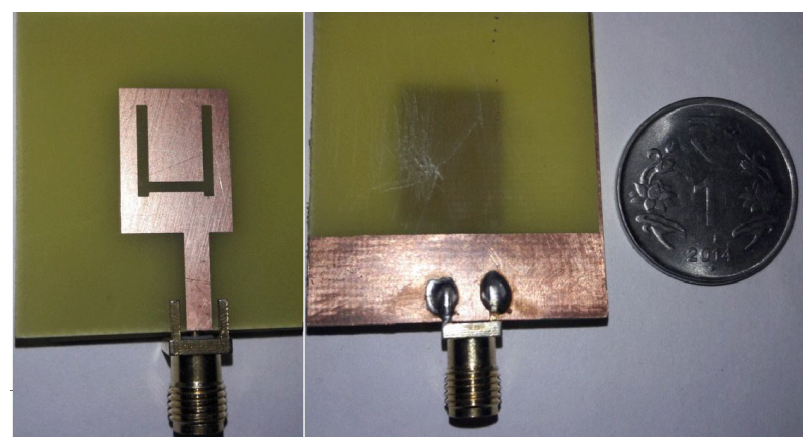

Figure 10.Prototype of fabricated bandnotch rectangular slot UWB antenna

Simulated and measured VSWR of band notch rectangular slot UWB antenna is shown in fig.11.The N9916A vector network analyser is used for measurement.From fig. 11 it is clearly observed that measured results are in good agreement with the simulated results.

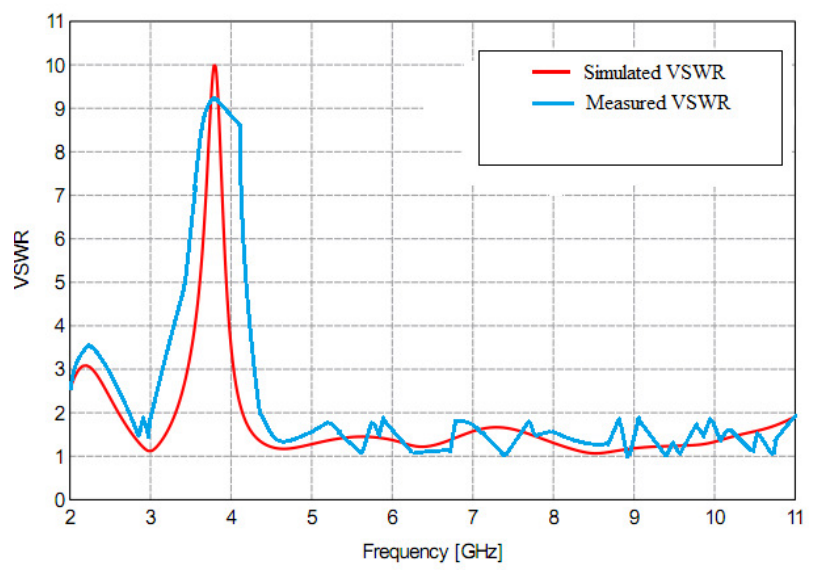

Figure 11.Measured and simulated VSWR of bandnotch rectangular slot UWB antenna

\section{CONCLUSIONS}

A small and compact rectangular slot antenna with band notched characteristics has been designed, simulated,fabricated and measured.The results show that by cutting wide rectangular slot in ground plane the impedance bandwidth is improved from 2.9 to $11.2 \mathrm{GHz}$.Introducing modified $U$ slot in the radiating patch and optimizing the width of modified U slot,good band rejection characteristics from $3.3-4.15 \mathrm{GHz}$ obtained.Good radiation characteristics are obtained along $\mathrm{E}$ and $\mathrm{H}$ plane.The proposed antenna shows stable efficiency and gain at all desired frequency bands except notched frequency band to minimize the interferences between UWB system and narrowband systems(WiMAX and C-band).This makes proposed antenna a good candidate for personal wireless application.

\section{ACKNOWLEDGEMENTS}

I would like to thank Prof.Rekha Labade, Head of E\&TC Department and my project guide Prof.Ramesh Pawase for helpful discussion. I would also like to thank the anonymous reviewers for their valuable comments to improve this paper. 


\section{REFERENCES}

[1] "Federal Communication Commission revision of Part 15 of the commission's rules regarding ultrawideband transmission systems,"FCC,Washington DC first Report and Order FCC,02.V48,2002.

[2] Rezaul Azim,Mohammad Tariqul Islam,Senior Member,IEEE,\&Ahmed Toaha Mobashshsher, "Design of a Dual Band-Notch UWB Slot Antenna by Means of Simple Parasitic Slits",IEEE ANTENNAS AND WIRELESS PROPAGATION LETTERS,VOL.12,2013.

[3] Peng Gao,Member,IEEE,Ling Xiong,Jianbo Dai,Shuang He,and Yi Zheng, "Compact Printed WideSlot UWB Antenna With 3.5/5.5-GHz Dual Band-Notched Characteristics", IEEE ANTENNAS AND WIRELESS PROPAGATION LETTERS,VOL.12,2013.

[4] Seyed Ramin Emadian \& Javad Ahmadi-Shokouh, "Very Small Dual Band Notched Rectangular Slot Antenna with Enhanced Impedance Bandwidth”,DOI 10.1109/TAP.2015.2456905,IEEE Transaction on Antenna and Propagation.

[5] Reza Zaker,Changiz Ghobadi,and Javad Nourinia, "Bandwidth Enhancement of Novel Compact Single and Dual Band-Notched Printed Monopole Antenna With a pair of L-shaped Slots",IEEE TRANSACTION ON ANTENNAS AND PROPAGATION,VOL.57,NO.12,DECEMBER 2009.

[6] M.Ojaroudi,Sh.Yzdanifard,N.Ojaroudi,and R.A.Sadeghzadeh, "Band-notched small square-ring antenna with a pair of T- shaped strips protruded inside the square ring for UWB applications,"IEEE Antennas Wireless Propag.Lett.,vol.10,pp.227-230,2011.

[7] M.Ojaroudi, "Printed monopole antenna with a novel band-notched folded trapezoid ultrawideband,"J.Electromagn.Waves Appl.,vol.23,pp.2513-2522,2009.

[8] Rekha.P Labade, Dr.S.B.Deosarkar, Dr.Narayan Pishoroty,Dr.Akshay Malhotra, "A Novel Integrated Bluetooth Dual Band UWB Antenna for Wireless Communication" International Journal of Microwave and Optical Technology,Vol.10,No.3,pp-195-201,May 2015.

[9] Rekha.P Labade, Dr. S.B.Deosarkar,Dr.Narayan Pishoroty,Dr. Akshay Malhotra, "Design and Implementation of an Integrated Bluetooth Ultrawideband Monopole Antenna" Australian Journal of Basic and Applied Sciences,8(15),60-66,2014.

[10] Zhi-Qiang and Cheng-Li Ruan, "A small integrated bluetooth and UWB antenna with WLAN band notched characteristics",Proceedings of International symposium on Signals,System and Electonics, 10.1109/ISSSE.2010.5638206,2010, 1971.

[11] G.Kumar and K.P.Ray, "Broadband Microstrip Antennas,"Artech House, 1992.

[12] C.A.Balanis, "Antenna Theory Analysis and Design," $3^{\text {rd }}$ Edition, John Wiley and Sons, New York, 1997.

[13] CAD-FEKO Simulation software,Version 7.0 UserManual.

\section{Authors}

\section{Short Biography}

Vaishali S Varpe has received her BE Degree in Electronics and Telecommunication in 2004 from University of Pune.Presently,she is pursuing ME(Microwave) from University of Pune.She is a PG student in Department of Electronics and Telecommunication at Amrutvahini college of Engineering.Her areas of interest are design of Microstrip antenna,Ultrawideband antenna and microwave engineering.

Rekha P Labade has received her BE Degree in Electronics in 1994 from University of Pune,(M.S) ME(Electronics) in 2004 from BAMU,Aurangabad(M.S.),India.Presently,she is pursuing Ph.D from Symbiosis International University.She is an assistant professor in Department Electronics and Telecommunication at Amrutvahini college of Engineering.She has 16 years of teaching experience.Her areas of interest are design of Microstrip antenna,Ultrawideband antenna and Microwave enigineering.

Ramesh Pawase has completed BE in Electronics from Amrutvahini College of Engineering,Sangamner.He is working as an Asst Professor in department of Electronics \& Telecommunication in Amrutvahini college of Engineering,Sangamner.His area of interest is Fiber Optic Communication.
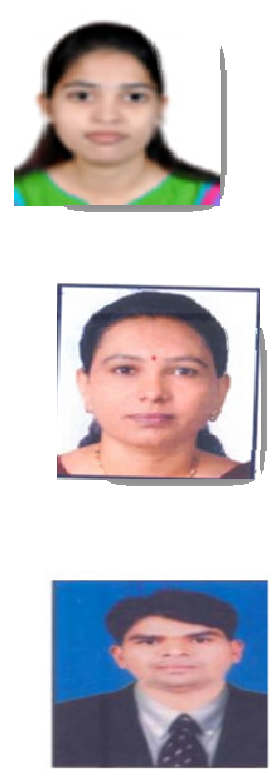